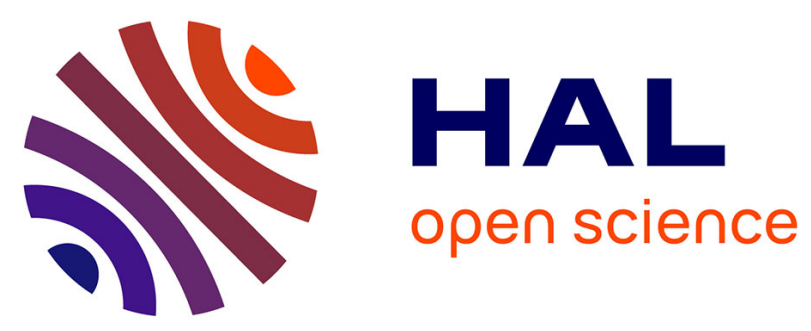

\title{
Control of the Speed of a Light-Induced Spin Transition through Mesoscale Core-Shell Architecture
}

\author{
Ashley Felts, Ahmed Slimani, John Cain, Matthew Andrus, Akhil Ahir, \\ Khalil Abboud, Mark Meisel, Kamel Boukheddaden, Daniel Talham
}

\section{- To cite this version:}

Ashley Felts, Ahmed Slimani, John Cain, Matthew Andrus, Akhil Ahir, et al.. Control of the Speed of a Light-Induced Spin Transition through Mesoscale Core-Shell Architecture. Journal of the American Chemical Society, 2018, 140 (17), pp.5814-5824. 10.1021/jacs.8b02148 . hal-03044409

\author{
HAL Id: hal-03044409 \\ https://hal.science/hal-03044409
}

Submitted on 25 Jun 2021

HAL is a multi-disciplinary open access archive for the deposit and dissemination of scientific research documents, whether they are published or not. The documents may come from teaching and research institutions in France or abroad, or from public or private research centers.
L'archive ouverte pluridisciplinaire HAL, est destinée au dépôt et à la diffusion de documents scientifiques de niveau recherche, publiés ou non, émanant des établissements d'enseignement et de recherche français ou étrangers, des laboratoires publics ou privés.

\section{(c)(1)}

Distributed under a Creative Commons Attribution| 4.0 International License 


\title{
Control of the Speed of a Light-Induced Spin Transition through Mesoscale Core-Shell Architecture
}

\author{
Ashley C. Felts, ${ }^{\dagger}$ Ahmed Slimani, ${ }^{\ddagger}$ John M. Cain, ${ }^{\dagger}$ Matthew J. Andrus, ${ }^{\dagger}$ Akhil R. Ahir, ${ }^{\dagger}$ Khalil A. Abboud, ${ }^{\dagger}$ \\ Mark W. Meisel, ${ }^{*}$, Kamel Boukheddaden, ${ }^{*},{ }^{\circledR}$ and Daniel R. Talham ${ }^{*}{ }^{\dagger}$ (৫) \\ ${ }^{\dagger}$ Department of Chemistry, University of Florida, Gainesville, Florida 32611-7200, United States \\ ${ }^{\ddagger}$ Laboratoire des Matériaux Multifonctionnels et Applications, Faculté des Sciences de Sfax, Université de Sfax, Route de la Soukra km \\ 3.5 - B.P. no. $1171-3000$ Sfax, Tunisia \\ ${ }^{\S}$ Department of Physics and the National High Magnetic Field Laboratory, University of Florida, Gainesville, Florida 32611-8440, \\ United States \\ "Groupe d'Etudes de la Matière Condensée, UMR CNRS 8635-Université de Versailles Saint Quentin En Yvelines, 45 Avenue des \\ Etats-Unis, 78035 Versailles, France
}

\begin{abstract}
The rate of the light-induced spin transition in a coordination polymer network solid dramatically increases when included as the core in mesoscale core-shell particles. A series of photomagnetic coordination polymer core-shell heterostructures, based on the light-switchable $\mathrm{Rb}_{a} \mathrm{Co}_{b}\left[\mathrm{Fe}(\mathrm{CN})_{6}\right]_{c} \cdot m \mathrm{H}_{2} \mathrm{O}$ ( $\left.\mathrm{RbCoFe}-\mathrm{PBA}\right)$ as core with the isostructural $\mathrm{K}_{j} \mathrm{Ni}_{k}\left[\mathrm{Cr}(\mathrm{CN})_{6}\right]_{l} \cdot n \mathrm{H}_{2} \mathrm{O}(\mathrm{KNiCr}-\mathrm{PBA})$ as shell, are studied using temperaturedependent powder X-ray diffraction and SQUID magnetometry. The core RbCoFe-PBA exhibits a charge transfer-induced spin transition (CTIST), which can be thermally and optically induced. When coupled to the shell, the rate of the optically induced transition from low spin to high spin increases. Isothermal relaxation from the optically induced high spin state of the core back to the low spin state and activation energies associated with the transition

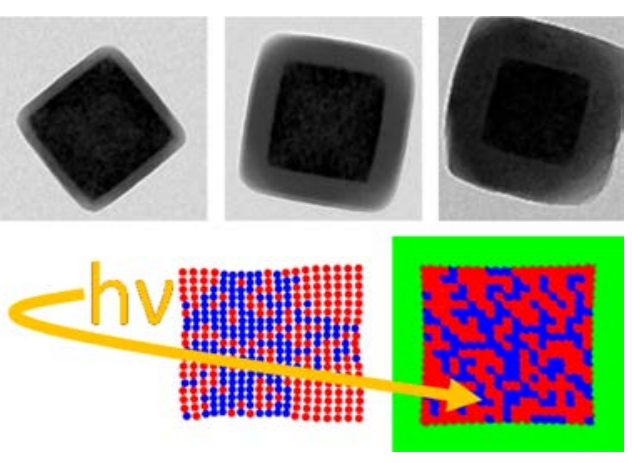
between these states were measured. The presence of a shell decreases the activation energy, which is associated with the elastic properties of the core. Numerical simulations using an electro-elastic model for the spin transition in core-shell particles supports the findings, demonstrating how coupling of the core to the shell changes the elastic properties of the system. The ability to tune the rate of optically induced magnetic and structural phase transitions through control of mesoscale architecture presents a new approach to the development of photoswitchable materials with tailored properties.
\end{abstract}

\section{INTRODUCTION}

Interest in solid state spin transition materials has long been associated with their spin-state bistability and the potential to record information readable with magnetic or colorimetric detection. $^{1-4}$ Beyond memory effects, the sensitivity of spin transitions to chemical changes, often when included in porous networks, has led to studies aimed at potential uses in chemical or environmental sensing and storage. ${ }^{5-11}$ However, an often overlooked feature of spin transition materials is the significant volume change associated with altered d-orbital occupancy and metal-ligand bonding in the two spin states. Volume changes of 5-10\% are common in spin transition network solids, with examples known up to $13 \%{ }^{12}$ Increasingly, attention has turned to the prospect of harvesting these significant volume changes, switchable with multiple stimuli, for use as mechanical actuators. $^{13-19}$

Recent examples of exploiting the spontaneous strain developed during a spin transition include integration into hybrid materials to influence electrical, ${ }^{20,21}$ optical, ${ }^{15,22-24}$ or magnetic ${ }^{25-31}$ properties with external stimuli. The ability to change volume or shape in response to a stimulus also opens the possibility of using spin transition materials as components of artificial muscles ${ }^{32}$ as was recently shown by Gural'skiy et al. ${ }^{17}$ through the development of an electromechanical actuator made of particles of the spin crossover complex $[\mathrm{Fe}-$ $\left.(\mathrm{Htrz})_{2}(\operatorname{trz})\right]\left(\mathrm{BF}_{4}\right)(\mathrm{Htrz}=1,2,4-4 \mathrm{H}$-triazole and trz $=1,2,4-$ triazole) dispersed in a poly(methyl methacrylate) matrix. Using light as the stimulus, the direct conversion of light to work was demonstrated by coupling spin transition materials with an inert material in bilayer cantilevers, ${ }^{15,18}$ which flex as the light induces the spin transition because of different coefficients of expansion. In another example, controlled heating with light was used to adjust the position of the interface between high spin and low spin domains in a single crystal, demonstrating the potential to use spin transition 
materials for precise actuation and for micropositioning. ${ }^{19}$ Such ideas represent innovative strategies for light energy harvesting and for photomechanically responsive materials.

These emerging applications all require the spin transition material to physically couple to other components. An interface with another material can influence the behavior of the spin transition compounds, especially as materials approach the nanoscale. $^{23,33-36}$ For example, Mallah and co-workers ${ }^{33}$ showed the temperature and order of the thermal spin transition can change when nanoscale particles of the spin crossover network $\mathrm{Fe}$ (pyrazine) $\mathrm{Pt}(\mathrm{CN})_{4}$ are contained in different matrices. The thermal spin transitions in $\mathrm{Fe}(\mathrm{II})$ triazole-based nanoparticles have also been shown to be affected by particle coatings. ${ }^{23,35,36}$ Several theoretical and numerical studies using different treatments have taken up the question of surface layers and matrix effects on spin transition particles, pointing to multiple effects. ${ }^{37-47}$ The elastic properties of both the active particle and the supporting matrix influence the mechanism of the cooperative solid-solid phase transition associated with the spin-transition. ${ }^{40-42}$ Modifying layers and supporting matrices can also influence the internal effective pressure on the nanoparticles through changes in surface energy, contributing to changes in the spin transition behavior. ${ }^{38,45,46}$ More work is required, both experimentally and theoretically, to fully understand the influence of surface modifiers and matrix effects on solid-state spin transitions.

The present study reports on the influence of a particle shell on a light-induced spin transition, showing for the first time that the speed of optical switching can be controlled by the presence of a shell. The active material is the cyanometallate coordination polymer, or Prussian blue analogue, $\mathrm{Rb}_{j} \mathrm{Co}_{k}[\mathrm{Fe}-$ $\left.(\mathrm{CN})_{6}\right]_{l} \cdot n \mathrm{H}_{2} \mathrm{O}(\mathrm{RbCoFe}-\mathrm{PBA})$ which exhibits a charge transfer induced spin transition (CTIST).$^{48-52}$ The cyanide bridged cobalt-iron pairs can exist as either $\mathrm{Fe}^{2+}-\mathrm{CN}-\mathrm{Co}^{3+}$ (LS) or $\mathrm{Fe}^{3+}-\mathrm{CN}-\mathrm{Co}^{2+}{ }_{(\mathrm{HS})}$ with the cobalt ion undergoing a spin transition. The spin transition causes a significant change in the $\mathrm{Co}-\mathrm{N}$ bond length and is responsible for a dramatic change in lattice constant from approximately $9.96 \AA$ in the low-spin phase to about $10.3 \AA$ in the high-spin phase. The transition between these charge states can be either thermally or optically activated, with the thermal transition occurring slightly below room temperature with significant hysteresis due to strong electron-lattice coupling. ${ }^{48-53}$ If the temperature is low enough, below about $150 \mathrm{~K}$, the metastable high-spin state can also be optically accessed and trapped. This optical CTIST is directly analogous to the light-induced excited spin state trapping (LIESST) ${ }^{54-56}$ transition seen in other spin crossover materials. When a shell of another Prussian blue analogue, $\mathrm{K}_{j} \mathrm{Ni}_{k}\left[\mathrm{Cr}(\mathrm{CN})_{6}\right]_{l} \cdot n \mathrm{H}_{2} \mathrm{O}$ ( $\left.\mathrm{KNiCr}-\mathrm{PBA}\right)$, is grown on the $\mathrm{RbCoFe}-\mathrm{PBA}$ core, the rate of the optical CTIST is enhanced by as much as 2 orders of magnitude. Experimental studies and application of theoretical modeling show the shell limits the extent of lattice contraction or expansion associated with the spin transition, changing the barrier to the thermal and optical transitions. The behavior can be tuned by changing the shell characteristics. The new findings show how varying the mesoscale architecture provides the ability to control the rate of optically induced structural phase transitions of potential importance for new photomechanically responsive materials and light-induced mechanical actuators.

\section{EXPERIMENTAL SECTION}

$\mathrm{RbCoFe}-\mathrm{PBA}$ and the $\mathrm{RbCoFe} @ \mathrm{KNiCr}-\mathrm{PBA}$ core-shell particles were synthesized using methods previously reported by Risset et al. ${ }^{57}$ This successive seed-growth method uses a portion of the preceding sample as the seeds for the next stage of shell growth to ensure similar core and interface compositions in all core-shell particles, even as shell thickness changes. ${ }^{58}$ Two series of samples were prepared and studied. The first series is composed of five samples, including uncoated RbCoFe-PBA particles, 1, and RbCoFe@KNiCr-PBA particles with four different shell thicknesses, $2-5 .{ }^{59}$ A second series was synthesized featuring a similar $\mathrm{RbCoFe}-\mathrm{PBA}$ core batch, $\mathbf{6}$, with three shell thicknesses, 7-9.

Sample 1. $\mathrm{Rb}_{0.3} \mathrm{Co}\left[\mathrm{Fe}(\mathrm{CN})_{6}\right]_{0.8}\left(1.4 \mathrm{H}_{2} \mathrm{O}\right) \cdot 1.8 \mathrm{H}_{2} \mathrm{O}$. Particle Size 160 (SD20) nm. Purple powder. IR (KBr): $2159 \mathrm{~cm}^{-1}(\nu \mathrm{CN}$, $\left.\mathrm{Co}_{(\mathrm{HS})}^{\mathrm{II}}-\mathrm{NC}-\mathrm{Fe}^{\mathrm{III}}\right) ; 2113 \mathrm{~cm}^{-1}\left(\nu \mathrm{CN}, \mathrm{Co}^{\mathrm{III}}{ }_{(\mathrm{LS})}-\mathrm{NC}-\mathrm{Fe}^{\mathrm{II}}\right) ; 2094$ $\mathrm{cm}^{-1}\left(\nu \mathrm{CN}, \mathrm{Co}^{\mathrm{II}}-\mathrm{NC}-\mathrm{Fe}^{\mathrm{II}}\right)$. EDS (Co/Fe) 48.70:36.22. Anal. Calcd: C, 18.48; H, 2.07; N, 21.56. Found: C, 18.27; H, 2.12; N, 20.92.

Sample 2. $\mathrm{Rb}_{0.3} \mathrm{Co}\left[\mathrm{Fe}(\mathrm{CN})_{6}\right]_{0.8}\left(1.4 \mathrm{H}_{2} \mathrm{O}\right) \cdot 1.8 \mathrm{H}_{2} \mathrm{O} @ \mathrm{~K}_{0.3} \mathrm{Ni}[\mathrm{Cr}-$ $\left.(\mathrm{CN})_{6}\right]_{0.8}\left(1.4 \mathrm{H}_{2} \mathrm{O}\right) \cdot n \mathrm{H}_{2} \mathrm{O}$. Particle size $200(\mathrm{SD} 20) \mathrm{nm}$. Shell thickness $15 \pm 5 \mathrm{~nm}$. Purple powder. IR $(\mathrm{KBr}): 2159 \mathrm{~cm}^{-1}\left(\nu \mathrm{CN} \mathrm{Co}^{\mathrm{II}}{ }_{(\mathrm{HS})}-\right.$ $\left.\mathrm{NC}-\mathrm{Fe}^{\mathrm{III}}\right) ; 2113 \mathrm{~cm}^{-1}\left(\nu \mathrm{CN}, \mathrm{Co}^{\mathrm{III}}(\mathrm{LS})-\mathrm{NC}-\mathrm{Fe}^{\mathrm{II}}\right) ; 2094 \mathrm{~cm}^{-1}(\nu \mathrm{CN}$, $\left.\mathrm{Co}^{\mathrm{II}}-\mathrm{NC}-\mathrm{Fe}^{\mathrm{II}}\right) ; 2174 \mathrm{~cm}^{-1}\left(\nu \mathrm{CN}, \mathrm{Ni}^{\mathrm{II}}-\mathrm{NC}-\mathrm{Cr}^{\mathrm{III}}\right)$. EDS $(\mathrm{RbCoFe} /$ $\mathrm{KNiCr}) 68: 32$.

Sample 3. $\mathrm{Rb}_{0.3} \mathrm{Co}\left[\mathrm{Fe}(\mathrm{CN})_{6}\right]_{0.8}\left(1.4 \mathrm{H}_{2} \mathrm{O}\right) \cdot 1.8 \mathrm{H}_{2} \mathrm{O} @ \mathrm{~K}_{0.3} \mathrm{Ni}[\mathrm{Cr}-$ $\left.(\mathrm{CN})_{6}\right]_{0.8}\left(1.4 \mathrm{H}_{2} \mathrm{O}\right) \cdot n \mathrm{H}_{2} \mathrm{O}$. Particle size $240(\mathrm{SD} 30) \mathrm{nm}$. Shell thickness $40 \pm 5 \mathrm{~nm}$. Purple powder. IR (KBr): $2159 \mathrm{~cm}^{-1}\left(\nu \mathrm{CN}, \mathrm{Co}_{(\mathrm{HS})}{ }^{\mathrm{II}}\right.$ $\left.\mathrm{NC}-\mathrm{Fe}^{\mathrm{III}}\right) ; 2113 \mathrm{~cm}^{-1}\left(\nu \mathrm{CN}, \mathrm{Co}{ }_{(\mathrm{IIS})}^{\mathrm{III}}-\mathrm{NC}-\mathrm{Fe}^{\mathrm{II}}\right) ; 2094 \mathrm{~cm}^{-1}(\nu \mathrm{CN}$ $\left.\mathrm{Co}^{\mathrm{II}}-\mathrm{NC}-\mathrm{Fe}^{\mathrm{II}}\right) ; 2174 \mathrm{~cm}^{-1}\left(\nu \mathrm{CN}, \mathrm{Ni}^{\mathrm{II}}-\mathrm{NC}-\mathrm{Cr}^{\mathrm{III}}\right)$. EDS ( $\mathrm{RbCoFe} /$ $\mathrm{KNiCr})$ 50:50.

Sample 4. $\mathrm{Rb}_{0.3} \mathrm{Co}\left[\mathrm{Fe}(\mathrm{CN})_{6}\right]_{0.8}\left(1.4 \mathrm{H}_{2} \mathrm{O}\right) \cdot 1.8 \mathrm{H}_{2} \mathrm{O} @ \mathrm{~K}_{0.3} \mathrm{Ni}[\mathrm{Cr}-$ $\left.(\mathrm{CN})_{6}\right]_{0.8}\left(1.4 \mathrm{H}_{2} \mathrm{O}\right) \cdot n \mathrm{H}_{2} \mathrm{O}$. Particle size $280(\mathrm{SD} 20) \mathrm{nm}$. Shell thickness $60 \pm 5 \mathrm{~nm}$. Purple powder. IR (KBr): $2159 \mathrm{~cm}^{-1}\left(\nu \mathrm{CN}, \mathrm{Co}_{(\mathrm{HS})}{ }^{\mathrm{II}}\right.$ $\left.\mathrm{NC}-\mathrm{Fe}^{\mathrm{III}}\right) ; 2113 \mathrm{~cm}^{-1}\left(\nu \mathrm{CN}, \mathrm{Co}^{\mathrm{III}}(\mathrm{LS})-\mathrm{NC}-\mathrm{Fe}^{\mathrm{II}}\right) ; 2094 \mathrm{~cm}^{-1}(\nu \mathrm{CN}$, $\left.\mathrm{Co}^{\mathrm{II}}-\mathrm{NC}-\mathrm{Fe}^{\mathrm{II}}\right) ; 2174 \mathrm{~cm}^{-1}\left(\nu \mathrm{CN}, \mathrm{Ni}^{\mathrm{II}}-\mathrm{NC}-\mathrm{Cr}^{\mathrm{III}}\right)$. EDS $(\mathrm{RbCoFe} /$ $\mathrm{KNiCr}) 31: 69$.

Sample 5. $\mathrm{Rb}_{0.3} \mathrm{Co}\left[\mathrm{Fe}(\mathrm{CN})_{6}\right]_{0.8}\left(1.4 \mathrm{H}_{2} \mathrm{O}\right) \cdot 1.8 \mathrm{H}_{2} \mathrm{O} @ \mathrm{~K}_{0.3} \mathrm{Ni}[\mathrm{Cr}-$ $\left.(\mathrm{CN})_{6}\right]_{0.8}\left(1.4 \mathrm{H}_{2} \mathrm{O}\right) \cdot n \mathrm{H}_{2} \mathrm{O}$. Particle size $350(\mathrm{SD} 40) \mathrm{nm}$. Shell thickness $95 \pm 5 \mathrm{~nm}$. Purple powder. IR (KBr): $2159 \mathrm{~cm}^{-1}\left(\nu \mathrm{CN}, \mathrm{Co}^{\mathrm{II}}{ }_{(\mathrm{HS})}-\right.$ $\left.\mathrm{NC}-\mathrm{Fe}^{\mathrm{III}}\right) ; 2113 \mathrm{~cm}^{-1}\left(\nu \mathrm{CN}, \mathrm{Co}^{\mathrm{III}}(\mathrm{LS})-\mathrm{NC}-\mathrm{Fe}^{\mathrm{II}}\right) ; 2094 \mathrm{~cm}^{-1}(\nu \mathrm{CN}$, $\left.\mathrm{Co}^{\mathrm{II}}-\mathrm{NC}-\mathrm{Fe}^{\mathrm{II}}\right) ; 2174 \mathrm{~cm}^{-1}\left(\nu \mathrm{CN}, \mathrm{Ni}^{\mathrm{II}}-\mathrm{NC}-\mathrm{Cr}{ }^{\mathrm{III}}\right)$. EDS (RbCoFe/ $\mathrm{KNiCr}) 20: 80$.

Sample 6. $\mathrm{Rb}_{0.19} \mathrm{Co}\left[\mathrm{Fe}(\mathrm{CN})_{6}\right]_{0.73}\left(1.6 \mathrm{H}_{2} \mathrm{O}\right) \cdot 1.3 \mathrm{H}_{2} \mathrm{O}$. Particle size $122 \pm 12 \mathrm{~nm}$. Purple powder. IR (KBr): $2159 \mathrm{~cm}^{-1}\left(\nu \mathrm{CN}, \mathrm{Co}^{\mathrm{II}}(\mathrm{HS})-\right.$ $\left.\mathrm{NC}-\mathrm{Fe}^{\mathrm{III}}\right) ; 2114 \mathrm{~cm}^{-1}\left(\nu \mathrm{CN}, \mathrm{Co}^{\mathrm{III}}{ }_{(\mathrm{LS})}-\mathrm{NC}-\mathrm{Fe}^{\mathrm{II}}\right) ; 2093 \mathrm{~cm}^{-1}(\nu \mathrm{CN}$, $\mathrm{Co}^{\mathrm{II}}-\mathrm{NC}-\mathrm{Fe}^{\mathrm{II}}$ ). EDS (Co/Fe) 58:42. TGA: $18.6 \%$ loss near $100{ }^{\circ} \mathrm{C}$.

Sample 7. $\mathrm{Rb}_{0.19} \mathrm{Co}\left[\mathrm{Fe}(\mathrm{CN})_{6}\right]_{0.73}\left(1.6 \mathrm{H}_{2} \mathrm{O}\right) \cdot 1.3 \mathrm{H}_{2} \mathrm{O} @ \mathrm{~K}_{0.19} \mathrm{Ni}[\mathrm{Cr}-$ $\left.(\mathrm{CN})_{6}\right]_{0.73}\left(1.6 \mathrm{H}_{2} \mathrm{O}\right) \cdot 2.7 \mathrm{H}_{2} \mathrm{O}$. Particle size $154 \pm 13 \mathrm{~nm}$. Shell thickness $15 \pm 5 \mathrm{~nm}$. Purple powder. IR (KBr): $2160 \mathrm{~cm}^{-1}\left(\nu \mathrm{CN}, \mathrm{Co}^{\mathrm{II}}{ }_{(\mathrm{HS})}-\right.$ $\left.\mathrm{NC}-\mathrm{Fe}^{\mathrm{III}}\right) ; 2113 \mathrm{~cm}^{-1}\left(\nu \mathrm{CN}, \mathrm{Co}_{(\mathrm{II})}^{\mathrm{III}}-\mathrm{NC}-\mathrm{Fe}^{\mathrm{II}}\right) ; 2094 \mathrm{~cm}^{-1}(\nu \mathrm{CN}$, $\left.\mathrm{Co}^{\mathrm{II}}-\mathrm{NC}-\mathrm{Fe}^{\mathrm{II}}\right) ; 2178 \mathrm{~cm}^{-1}\left(\nu \mathrm{CN}, \mathrm{Ni}^{\mathrm{II}}-\mathrm{NC}-\mathrm{Cr}^{\mathrm{III}}\right)$. ICP $(\mathrm{Co} / \mathrm{Ni})$ 1:0.67. TGA: $22.2 \%$ loss near $100{ }^{\circ} \mathrm{C}$.

Sample 8. $\mathrm{Rb}_{0.19} \mathrm{Co}\left[\mathrm{Fe}(\mathrm{CN})_{6}\right]_{0.73}\left(1.6 \mathrm{H}_{2} \mathrm{O}\right) \cdot 1.3 \mathrm{H}_{2} \mathrm{O} @ \mathrm{~K}_{0.13} \mathrm{Ni}[\mathrm{Cr}-$ $\left.(\mathrm{CN})_{6}\right]_{0.71}\left(1.7 \mathrm{H}_{2} \mathrm{O}\right) \cdot 2.5 \mathrm{H}_{2} \mathrm{O}$. Particle size $180 \pm 13 \mathrm{~nm}$. Shell thickness $29 \pm 5 \mathrm{~nm}$. Purple powder. IR $(\mathrm{KBr}): 2160 \mathrm{~cm}^{-1}\left(\nu \mathrm{CN}, \mathrm{Co}_{(\mathrm{HS})}{ }^{\mathrm{II}}\right.$ $\left.\mathrm{NC}-\mathrm{Fe}^{\mathrm{III}}\right) ; 2113 \mathrm{~cm}^{-1}\left(\nu \mathrm{CN}, \mathrm{Co}{ }^{\mathrm{III}}(\mathrm{LS})-\mathrm{NC}-\mathrm{Fe}^{\mathrm{II}}\right) ; 2095 \mathrm{~cm}^{-1}(\nu \mathrm{CN}$, $\left.\mathrm{Co}^{\mathrm{II}}-\mathrm{NC}-\mathrm{Fe}^{\mathrm{II}}\right) ; 2176 \mathrm{~cm}^{-1}\left(\nu \mathrm{CN}, \mathrm{Ni}^{\mathrm{II}}-\mathrm{NC}-\mathrm{Cr}^{\mathrm{III}}\right)$. ICP $(\mathrm{Co} / \mathrm{Ni})$ 1:1.78. TGA: $24.0 \%$ loss near $100{ }^{\circ} \mathrm{C}$.

Sample 9. $\mathrm{Rb}_{0.19} \mathrm{Co}\left[\mathrm{Fe}(\mathrm{CN})_{6}\right]_{0.73}\left(1.6 \mathrm{H}_{2} \mathrm{O}\right) \cdot 1.3 \mathrm{H}_{2} \mathrm{O} @ \mathrm{~K}_{0.08} \mathrm{Ni}[\mathrm{Cr}-$ $\left.(\mathrm{CN})_{6}\right]_{0.69}\left(1.8 \mathrm{H}_{2} \mathrm{O}\right) \cdot 2.1 \mathrm{H}_{2} \mathrm{O}$. Particle size $227 \pm 18 \mathrm{~nm}$. Shell thickness $52 \pm 5 \mathrm{~nm}$. Purple powder. IR (KBr): $2162 \mathrm{~cm}^{-1}\left(\nu \mathrm{CN}, \mathrm{Co}^{\mathrm{II}}{ }_{(\mathrm{HS})}-\right.$ $\left.\mathrm{NC}-\mathrm{Fe}^{\mathrm{III}}\right) ; 2118 \mathrm{~cm}^{-1}\left(\nu \mathrm{CN}, \mathrm{Co}{ }_{(\mathrm{IIS})}-\mathrm{NC}-\mathrm{Fe}^{\mathrm{II}}\right) ; 2098 \mathrm{~cm}^{-1}(\nu \mathrm{CN}$, $\left.\mathrm{Co}^{\mathrm{II}}-\mathrm{NC}-\mathrm{Fe}^{\mathrm{II}}\right) ; 2176 \mathrm{~cm}^{-1}\left(\nu \mathrm{CN}, \mathrm{Ni}^{\mathrm{II}}-\mathrm{NC}-\mathrm{Cr}^{\mathrm{III}}\right)$. ICP $(\mathrm{Co} / \mathrm{Ni})$ 1:4.49. TGA: $24.2 \%$ loss near $100{ }^{\circ} \mathrm{C}$.

Transmission electron microscopy (TEM) was performed using a JEOL-2010F high-resolution transmission electron microscope at $200 \mathrm{kV}$. TEM samples were prepared by adding dropwise $40 \mu \mathrm{L}$ of a water solution $(1 \mathrm{~mL})$ containing $2 \mathrm{mg}$ of product dispersed by sonication to a grid (400 mesh copper with holey carbon support film from Ted-Pella, Inc.) and allowing each grid to dry. Energy-dispersive $\mathrm{X}$-ray spectroscopy (EDS) was performed using an Oxford Instru- 

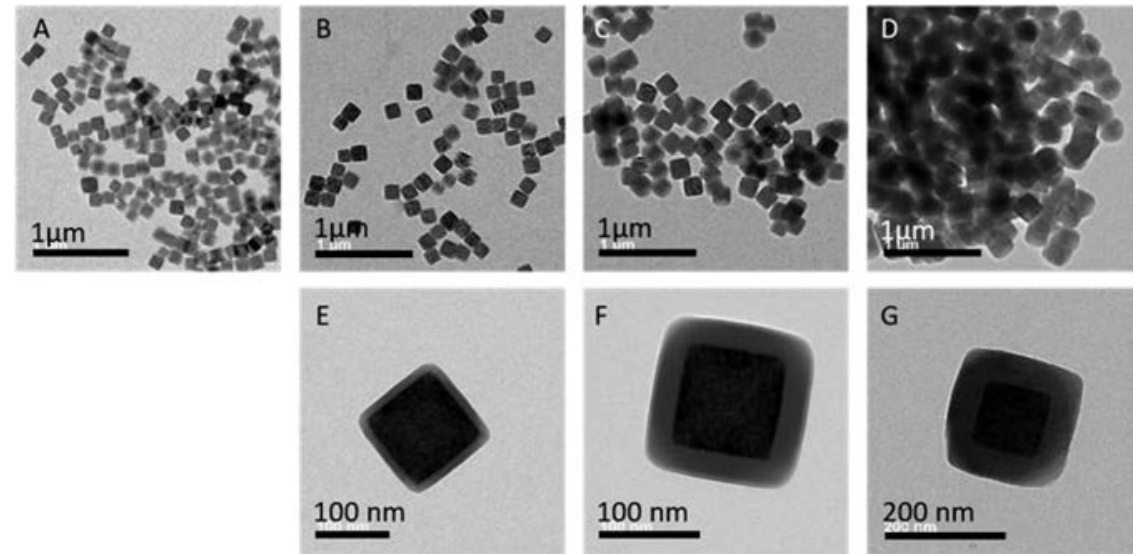

Figure 1. TEM images for samples 6-9. (A) Uncoated RbCoFe-PBA particles, sample 6. (B-D) RbCoFe@KNiCr-PBA core-shell particles, samples 7-9, shown with scale bars of $1 \mu \mathrm{m}$ and corresponding images $(\mathrm{E}-\mathrm{G})$ at higher magnification clearly revealing the core-shell morphology.

ments EDS X-ray Microanalysis System, which was coupled to the TEM microscope. No fewer than three scans were recorded on different parts of each sample and then averaged to give relative atomic percentages for the metallic elements. Inductively coupled plasma atomic emission spectroscopy (ICP) was performed on a VARIAN VISTA RL simultaneous spectrometer (Agilent Technologies, Santa Clara, CA) with a CCD detector. The wavelengths used for quantitative determination of cobalt were: 230.786, 237.863, and $238.892 \mathrm{~nm}$; for chromium: $267.716,276.653$, and $357.868 \mathrm{~nm}$; for iron: 238.204, 259.940, and $261.187 \mathrm{~nm}$; and for nickel: 221.648, 230.299 , and $231.604 \mathrm{~nm}$. The wavelengths were chosen so as to eliminate interferences from analyte and nonanalyte species present in the sample. Standard solutions of 100,10 , and $1 \mathrm{ppm}$ concentrations for each element measured were prepared from $1000 \mathrm{ppm}$ standard solutions obtained from Fluka Analytical. Thermal gravimetric analyses (TGA) were performed on a PerkinElmer TGA 7 thermogravimetric analyzer $(10 \mathrm{~K} / \mathrm{min}$ heating rate in nitrogen atmosphere). Average molecular formulas for samples 1-5 were determined based on relative metal ratios obtained from EDS as well as CHN or TGA to determine water content. Average molecular formulas for samples 6-9 were determined based on relative metal ratios obtained from ICP and water content from TGA. Alkali cation content was determined based on electroneutrality. Water content is reported as coordinated water, $\left(m \mathrm{H}_{2} \mathrm{O}\right)$, calculated based on relative metal ratios, and zeolitic water, $n \mathrm{H}_{2} \mathrm{O}$, which is the remaining water composition as found by TGA. Particle size was measured for at least 150 particles using ImageJ imaging software ${ }^{60}$ from TEM images taken of various areas in the sample. Shell thickness was determined by considering the difference between the average core-shell size and the average core particle size and dividing by two to reflect thickness on a per side basis. Fourier transform infrared (FTIR) spectroscopy was performed using a Nicolet 6700 Thermo Scientific spectrophotometer. Measurements were taken between 2500 and $1800 \mathrm{~cm}^{-1}$. Samples were prepared for FTIR measurements by suspending $1 \mathrm{mg}$ of each sample in acetone, depositing onto the surface of a $\mathrm{KBr}$ pellet, and allowing it to dry.

Synchrotron powder X-ray diffraction (PXRD) data were collected at beamline 17-BM at the Advanced Photon Source at Argonne National Laboratory. A flat-panel amorphous-Si area detector was positioned $500 \mathrm{~mm}$ from the sample. Calibration was performed using an NAC standard. Samples were loaded into polyimide capillaries ( $0.64 \mathrm{~mm}$ i.d.) and exposed to $\mathrm{X}$-rays of $\lambda=0.72808 \AA$ for no less than $5 \mathrm{~s}$ while the capillary was rocked a total of $5^{\circ}$. Temperature was regulated using an Oxford Cryosystems Cryostream nitrogen blower. Three sequences were used for PXRD data collection. For sequence 1 , data were collected as temperature was ramped at $2 \mathrm{~K} / \mathrm{min}$ from 300 to $100 \mathrm{~K}$, allowed to equilibrate, and ramped back to 300 at $2 \mathrm{~K} / \mathrm{min}$. For sequence 2, samples were irradiated at $100 \mathrm{~K}$ using a MEIJI FL$150(21 \mathrm{~V}, 150 \mathrm{~W})$ dual fiber optic source, delivering approximately $400 \mathrm{~mW}$ to the sample, for at least $30 \mathrm{~min}$ and up to $3 \mathrm{~h}$. During this time, the CTIST of the RbCoFe-PBA was observed, and irradiation was continued until the transition completed. For the uncoated particles, sample 6, each exposure was $20 \mathrm{~s}$, and patterns were only acquired once per minute to avoid X-ray induced relaxation back to the LS state. For sample 7, with the $15 \mathrm{~nm}$ shell, each exposure was $8 \mathrm{~s}$. For samples 8 and 9 , with the 29 and $52 \mathrm{~nm}$ shells, respectively, each exposure was $5 \mathrm{~s}$. No dark frames were collected in between subsequent light exposures of the core-shell samples in order to collect the next pattern as quickly as possible. For sequence 3 , samples were irradiated at $100 \mathrm{~K}$ for at least $30 \mathrm{~min}$ and up to $3 \mathrm{~h}$. During this time, the CTIST of the RbCoFe-PBA was observed, and irradiation was continued until the transition appeared complete. The temperature was then ramped to the isothermal relaxation temperature at $5 \mathrm{~K} / \mathrm{min}$ and held to monitor the relaxation of $\mathrm{RbCoFe}-\mathrm{PBA}$ from the optically induced HS state back to the LS state. Diffraction images were integrated using GSAS II, ${ }^{61}$ based on calibration parameters from a $\mathrm{LaB}_{6}$ standard. Stack plots were generated using Fit2D software. ${ }^{62}$ Unit-cell analysis was performed based on peak positions determined by Pawley refinement of each pattern.

Magnetization was performed on a Quantum Design Magnetic Property Measurement System (MPMS) model XL-7 superconducting quantum interference device (SQUID) magnetometer. Samples were field cooled from 300 to $100 \mathrm{~K}$ at $2 \mathrm{~K} / \mathrm{min}$ in a field of 100 Oe. They were then allowed to sit at $100 \mathrm{~K}$ for no less than $20 \mathrm{~min}$ before irradiation with a Fiber-Lite tungsten halogen lamp (EKE $21 \mathrm{~V}$ $150 \mathrm{~W}$ ), delivering nominally $4 \mathrm{~mW}$ to the sample, using an optical sample rod described elsewhere. ${ }^{63}$ The samples were irradiated for at least $2 \mathrm{~h}$, and then allowed to sit at $100 \mathrm{~K}$ with the light off for at least $1 \mathrm{~h}$, to demonstrate the persistent photoinduced effect. For isothermal relaxation studies, the samples were warmed at $2 \mathrm{~K} / \mathrm{min}$ to the temperature of interest, and held for up to $24 \mathrm{~h}$ to observe the relaxation from the optically induced metastable HS state back to the LS state.

\section{RESULTS}

Core-shell particles comprising the two Prussian blue analogues were prepared using the heterogeneous precipitation ${ }^{30,57}$ approach first developed by Catala and co-workers. $^{58,64}$ In this method, the shell component precipitates at the surface of suspended particles of the preformed core. To ensure the cores are uniform within a series with differing shell thicknesses, the product of one core-shell batch is used as the seed in the next batch. ${ }^{57}$ Two series of samples were prepared for this study. The first series, samples $\mathbf{1 - 5}$, with an average core size of $160 \mathrm{~nm}$, was used to study the thermally induced CTIST. A second series, samples 6-9, was prepared in order to perform more in-depth time-dependent studies on the optically induced CTIST and has an average core size of $122 \mathrm{~nm}$. The core-shell architecture of the particles is clearly visible in TEM 
images, Figure 1. Pawley refinements of PXRD patterns of each sample are consistent with two face centered cubic lattices, corresponding to the $\mathrm{RbCoFe}-\mathrm{PBA}$ cores and the $\mathrm{KNiCr}-\mathrm{PBA}$ shells, Figure S1.

Temperature dependent PXRD patterns were collected on samples 1-5 according to sequence 1 described in the Experimental Section, where data were collected upon cooling from 300 to $100 \mathrm{~K}$ and then again upon warming back to $300 \mathrm{~K}$. The resultant lattice parameters measured on the cooling part of the cycle are plotted in Figure 2. Since the

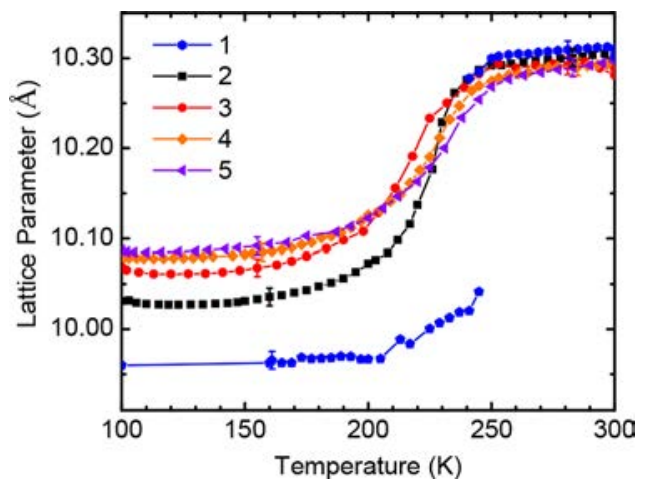

Figure 2. Unit cell parameter, $a$, vs temperature for RbCoFe-PBA in the uncoated particles, sample $\mathbf{1}$, and the core-shell particles, 2-5, obtained while cooling. The change in lattice parameter of the core is restricted with increasing shell thickness. Representative uncertainties are shown for high and low temperature data points.

particles are synthesized at room temperature with the $\mathrm{RbCoFe}-\mathrm{PBA}$ in the HS state, the $300 \mathrm{~K}$ core lattice parameter is approximately the same for each sample, near $10.30 \AA$. Upon cooling, the $\mathrm{RbCoFe}-\mathrm{PBA}$ contracts as it undergoes the thermal CTIST, but only the uncoated particles contract to the expected $9.96 \AA$ lattice constant below the transition. As a shell is added and its thickness increases, the contraction of the core is reduced. For the $95 \mathrm{~nm}$ shell sample, 5, the core lattice parameter at $100 \mathrm{~K}$ is $10.09 \AA$, significantly larger than for the uncoated particle. Therefore, the change in lattice parameter upon going through the CTIST transition is smaller for the core-shell particles and smallest for the thickest-shell sample. It is important to keep in mind that even though the structural changes differ, the magnetic spin transition is complete in each case, as was demonstrated in earlier work. ${ }^{59}$ The total change in lattice parameter for both the core and shell for each sample are compared in Figure 3.

The structural change associated with the thermal CTIST is first order for the uncoated particles, but the nature of the transition changes in the core-shell particles, as seen in the comparison in Figure 4. For the uncoated particles, the transition is completed over a relatively narrow temperature range, between approximately 255 and $240 \mathrm{~K}$, through which distinct diffraction from both the HS and LS phases is observed, indicating the coexistence of coherent domains of both phases.

In contrast, the transition in the $\mathrm{RbCoFe} @ \mathrm{KNiCr}-\mathrm{PBA}$ particles is gradual, completing over a much wider temperature range from approximately 260 to $175 \mathrm{~K}$, with only a single diffraction pattern recorded at each temperature corresponding to lattice parameters intermediate to the HS and LS limits.

The light-induced CTIST was monitored by recording timedependent PXRD patterns of samples 6-9 at $100 \mathrm{~K}$, cooling the sample according to sequence 2 described in the

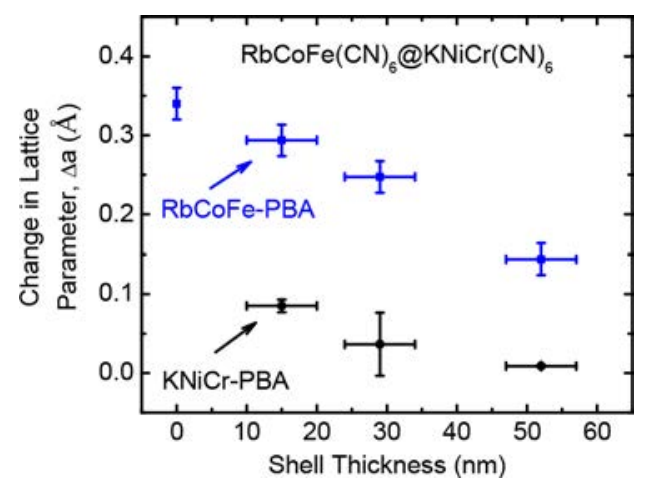

Figure 3. Difference in the unit cell parameter $(\Delta a)$ vs shell thickness for samples 6-9 between particles with the RbCoFe-PBA core in the $\mathrm{HS}$ phase measured at $300 \mathrm{~K}$ and in the LS phase measured at $100 \mathrm{~K}$. Changes in both the $\mathrm{RbCoFe}-\mathrm{PBA}$ core and $\mathrm{KNiCr}-\mathrm{PBA}$ shell are plotted. Changes to both the core and the shell are dampened with increasing shell thickness.

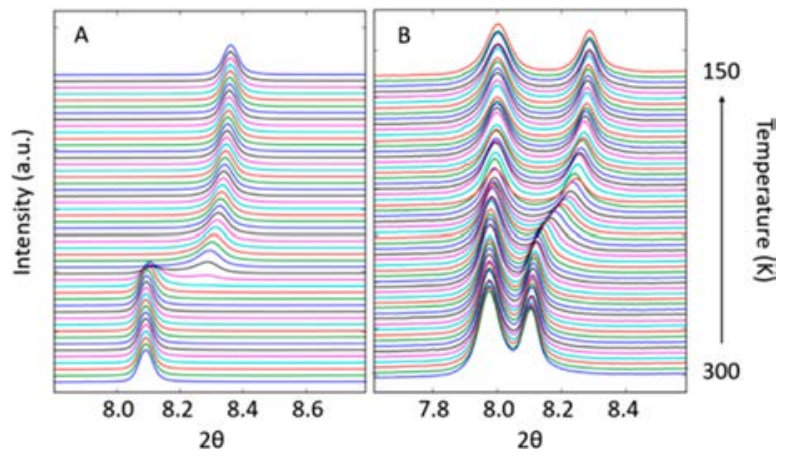

Figure 4. Stack plots showing the evolution of the 200 reflection as a function of temperature for $(\mathrm{A})$, the uncoated $\mathrm{RbCoFe}-\mathrm{PBA}$, sample 6 and (B) RbCoFe@KNiCr-PBA core-shell sample 8, from $300 \mathrm{~K}$ (bottom) to $150 \mathrm{~K}$ (top). The thermally induced transition of the uncoated particles is discontinuous, while the transition of the coreshell particles is continuous. The uncoated RbCoFe-PBA particles undergo a highly cooperative transition, with HS and LS regions detectable by PXRD during the transition. For (B), reflections from both the core, high $2 \theta$, and shell, low $2 \theta$, are seen. The presence of the shell reduces the cooperativity of the RbCoFe-PBA spin transition.

Experimental Section. Figure 5 shows the 200 reflection of patterns taken before the samples are irradiated with white light and monitors changes at increasing radiation times for the uncoated CoFe-PBA, sample 6, and two core-shell samples, 7 and 8. Upon irradiation, it takes $2-3 \mathrm{~min}$ for the uncoated particles to switch completely. In contrast, the core-shell particles show a markedly faster transition, completing in less than $20 \mathrm{~s}$ for sample 7 , and less than $5 \mathrm{~s}$ for sample $\mathbf{8}$, effectively before the first X-ray scan was complete.

The intrinsic kinetics of the light-induced LS-HS transition are difficult to quantify, requiring quantitative delivery of light to powdered samples. The light-induced transition rates can change with slight differences in sample packaging or sample mounting, for example. Furthermore, the efficiency of light absorption by the CTIST active material can change with the addition of shell. With the characteristic rate for the forward process difficult to quantify, isothermal relaxation studies were used to study the reverse process, the return from the metastable light-induced HS state back to the LS state. Following cooling of the sample to $100 \mathrm{~K}$ and irradiation to generate the light-induced HS state according to sequence 3 in 


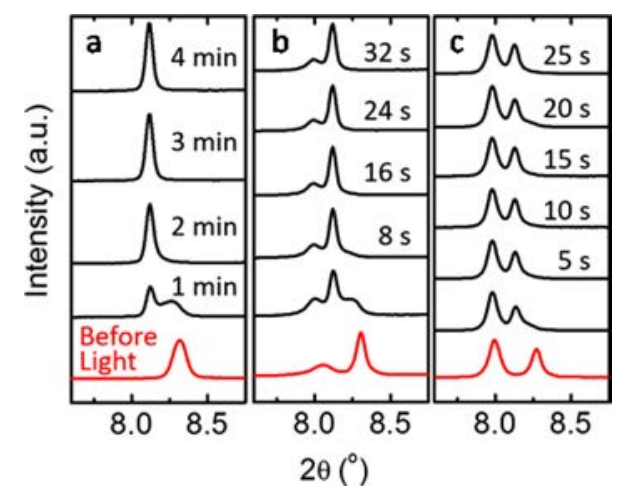

Figure 5. Plot of the progress of the photoinduced transition at $100 \mathrm{~K}$ as a function of time, monitoring the 200 reflection for (a) uncoated $\mathrm{RbCoFe}-\mathrm{PBA},(\mathrm{b}) \mathrm{RbCoFe} @ \mathrm{KNiCr}-\mathrm{PBA}$ core-shell sample with $15 \mathrm{~nm}$ shells, and (c) RbCoFe@KNiCr-PBA core-shell sample with $29 \mathrm{~nm}$ shells. The transition of the uncoated particles takes several minutes to complete, whereas the core-shell samples are complete in seconds.

the Experimental Section, samples were warmed to different target temperatures and PXRD patterns were collected at regular intervals to determine unit cell parameters as a function of time. For each of the core-shell samples, the starting and ending values of the cell parameters were used to generate plots of HS-state fraction as a function of time, Figure 6 and

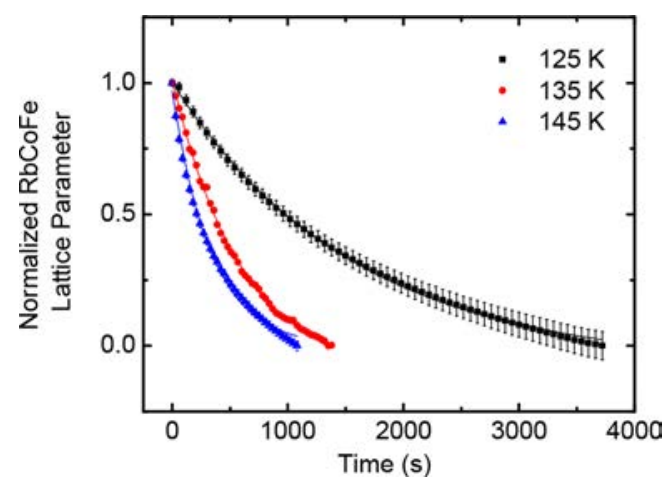

Figure 6. Normalized cubic lattice parameter vs time monitoring the isothermal relaxation from the metastable HS state of RbCoFe@ $\mathrm{KNiCr}$-PBA sample 8, with a $29 \mathrm{~nm}$ shell, at three temperatures. Lines through the data are single exponential fits, parameters for which are reported in Table 1.

Figure S2, which could then be fit with an exponential decay to determine time constants for each sample at each of the target temperatures, Table 1. Arrhenius plots, Figure S3, were then used to determine the activation energies for the HS to LS thermal decay, also shown in Table 1.
For the uncoated particles, sample 6, magnetometry was used to monitor the HS to LS relaxation, as it proved easier than fitting and quantifying each PXRD pattern with two distinct structures corresponding to the coexisting phases as a function of time. To verify whether the magnetometry and structural measurements monitor the same process, HS to LS relaxation of the core-shell sample 7 was also followed by magnetometry, Figure S4, and Arrhenius analysis, Figure S5, confirms both measurements yield the same activation energy (Table 1). The shape of the relaxation curve of the uncoated particles is different from those of the core-shell particles, displaying a sigmoidal shape seen before for CoFe-PBA analogues, ${ }^{65}$ and other spin-crossover solids, ${ }^{45,49}$ which reflects a high level of cooperativity associated with structural change, Figure 7.

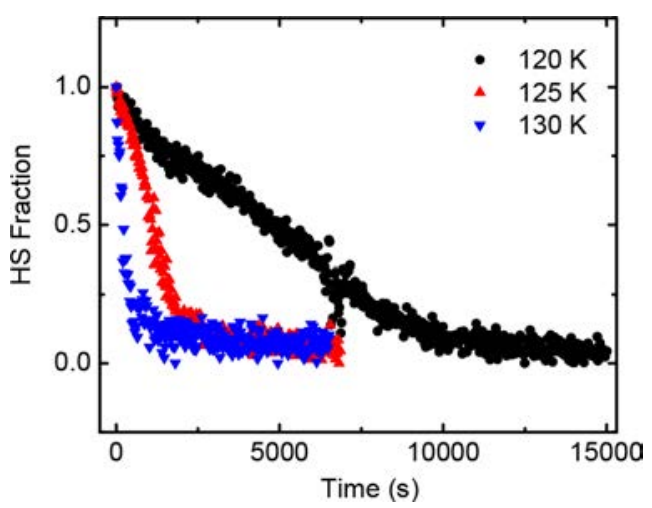

Figure 7. Normalized cubic lattice parameter vs time monitoring the isothermal relaxation from the metastable HS state of uncoated $\mathrm{RbCoFe}$ sample 6 at three temperatures. The relaxation shows a distinct sigmoidal shape, unlike the single exponential decay observed for the core-shell particles. The sigmoidal deviations reflect the strong cooperativity of the spin transition in the uncoated particles.

Furthermore, the activation energy for the isothermal relaxation process is significantly higher for the uncoated particles, 39.4 $\mathrm{kJ} / \mathrm{mol}$, compared to $16.7 \mathrm{~kJ} / \mathrm{mol}$ for the core-shell sample with the thinnest shell. The activation energy decreases even further as the NiCr-PBA shell becomes thicker, reaching $8.3 \mathrm{~kJ} /$ mol for the sample with the $52 \mathrm{~nm}$ shell as seen in Figure 8, which shows the activation energy as a function of shell thickness.

\section{DISCUSSION}

The key finding of the present study is the rate of the photoinduced CTIST in RbCoFe-PBA particles increases when the particles are coated with a NiCr-PBA shell. The rate enhancement can be attributed to a decrease in the elastic barrier to the structural phase change associated with the spintransition. The normally large difference in lattice constant between HS and LS states of CoFe-PBA, $\Delta a=0.34 \AA$,

Table 1. Isothermal Relaxation Data for Samples 6-9

\begin{tabular}{|c|c|c|c|c|c|c|}
\hline shell thickness, measurement technique & $1 / \tau_{0}, 120 \mathrm{~K}\left(\mathrm{~s}^{-1}\right)$ & $1 / \tau_{0}, 125 \mathrm{~K}\left(\mathrm{~s}^{-1}\right)$ & $1 / \tau_{0}, 130 \mathrm{~K}\left(\mathrm{~s}^{-1}\right)$ & $1 / \tau_{0}, 135 \mathrm{~K}\left(\mathrm{~s}^{-1}\right)$ & $1 / \tau_{0}, 145 \mathrm{~K}\left(\mathrm{~s}^{-1}\right)$ & $E_{\mathrm{a}}\left(\mathrm{kJ} \mathrm{mol}{ }^{-1}\right)$ \\
\hline uncoated, SQUID & $1.8 \times 10^{-4}$ & $8.7 \times 10^{-4}$ & $3.6 \times 10^{-3}$ & - & - & $39.4 \pm 1.0$ \\
\hline $15 \mathrm{~nm}$ shell, SQUID & & $5.9 \times 10^{-4}$ & - & $1.9 \times 10^{-3}$ & & $16.7 \pm 1.8^{a}$ \\
\hline $15 \mathrm{~nm}$ shell, PXRD & - & $9.9 \times 10^{-4}$ & - & $3.4 \times 10^{-3}$ & - & $17.2 \pm 1.9^{a}$ \\
\hline $29 \mathrm{~nm}$ shell, PXRD & - & $6.4 \times 10^{-4}$ & - & $1.7 \times 10^{-3}$ & $3.0 \times 10^{-3}$ & $12.0 \pm 1.3$ \\
\hline $52 \mathrm{~nm}$ shell, PXRD & $2.4 \times 10^{-3}$ & $3.2 \times 10^{-3}$ & - & $3.4 \times 10^{-3}$ & - & $7.9 \pm 0.4$ \\
\hline
\end{tabular}

${ }^{a}$ Based on measurements at two temperatures. 


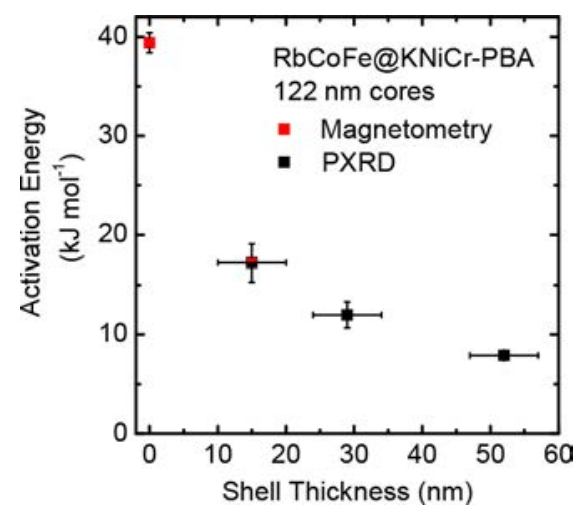

Figure 8. Activation energy vs shell thickness for the relaxation from the metastable HS state of $\mathrm{RbCoFe}-\mathrm{PBA}$ as extracted from Arrhenius plots for samples 6-9. The activation energy associated with the $\mathrm{RbCoFe}-\mathrm{PBA}$ core transition decreases with increasing shell thickness. The points in black are determined using PXRD data, while the points in red are determined from SQUID magnetometry.

decreases to as little as $\Delta a=0.14 \AA$ in the core-shell particles, which reduces the rigidity of the LS state, lowering the elastic barrier between the LS and HS phases. These conclusions are discussed in more detail in the following sections and are supported by an electro-elastic model for solid-state spin transition networks applied to a 2D lattice model of the coreshell particles. We begin by introducing the electro-elastic model and then discuss the changing elastic properties of the lattice as observed in the experimental measurements.

The Electro-Elastic Model. The structural interplay between the core and the shell, observed experimentally, was supported by numerical simulations based on an electro-elastic model. ${ }^{66}$ Details of the model appear in earlier papers, ${ }^{41,42,66}$ so the current discussion is limited to a brief outline of the approach, including some alterations specific to the lightinduced process. The core-shell nanoparticle is modeled by a regular $2 \mathrm{D}$ square lattice whose nodes are coupled via springs moving only inside the plane. Each node has four nearest neighbors (nn) and four next-nearest neighbors (nnn), except those at the surface. Each node of the core represents a spin transition atom that may have two spin states, high-spin (HS) or low-spin (LS), described by the respective eigenvalues +1 and -1 of an associated fictitious spin $S$. Metal-ligand bond distances are larger in the HS state than in the LS state so the equilibrium distance between nodes, $R_{0}$, differs depending on spin state of its neighbors. The nn, $R_{0}\left(S_{i}, S_{j}\right)$, and nnn, $R_{0}^{\prime}\left(S_{i}, S_{k}\right)$, distances will have different values depending on the local spin states and the nn distances are designated $R_{0}(+1 ;+1)=R_{\mathrm{HH}}$, $R_{0}(+1 ;-1)=R_{0}(-1 ;+1)=R_{\mathrm{HL}}$ and $R_{0}(-1 ;-1)=R_{\mathrm{LL}}$ corresponding to separations between HS-HS, HS-LS, and LS-LS sites. In contrast, the shell is assumed to be magnetically inactive and assigned a lattice parameter similar to that of the core in the HS state.

The model links the atoms by springs whose stiffness, $A_{i j}\left(S_{i}, S_{j}\right)$ for $\mathrm{nn}$ and $B_{i k}\left(S_{i} S_{k}\right)$ for $\mathrm{nnn}$, depend on the instantaneous distance between the nodes. Hence, the total Hamiltonian has the following form,

$$
\begin{aligned}
H= & \sum_{i} \frac{\left(\Delta-k_{\mathrm{B}} T \ln g\right)}{2} S_{i}+\sum_{i, j} A_{i j}\left[r_{i j}-R_{0}\left(S_{i}, S_{j}\right)\right]^{2} \\
& +\sum_{i, k} B_{i k}\left[r_{i k}-R_{0}^{\prime}\left(S_{i}, S_{k}\right)\right]^{2}
\end{aligned}
$$

The first term on the right-hand side contains the effective contribution of the ligand field energy, $\Delta$, and favors the LS state. This contribution competes with the entropic term $k_{\mathrm{B}} T \ln$ $g$, which stabilizes the HS state at high temperature, where $k_{\mathrm{B}}$ is the Boltzmann constant, $T$ the temperature, and $g$ is the degeneracy ratio between the HS and LS states. The second and third terms describe the elastic interactions between $\mathrm{nn}$ and nnn sites, respectively, using $r_{i j}=\left\|\vec{r}_{i}-\vec{r}_{j}\right\|$ (or $r_{i k}$ ) as the instantaneous distance between two nn (or nnn) sites. Monte Carlo procedures are run over the spin and position variables, repeating several times to reach the equilibrium mechanics. Visiting all the nodes of the lattice for a spin change is defined as one Monte Carlo step, MCS. For temperature sweeps, $10^{3}$ MCS were implemented for each temperature.

The thermal transition was modeled using a core with a side length of $L_{\mathrm{c}}=19 \mathrm{~nm}$ (19 nodes) while varying the thickness of the shell, $\omega$, in the range $[0-13] \mathrm{nm}$. The thermal variation of the HS fraction, $n_{\mathrm{HS}}$, as a function of the shell thickness is summarized in Figure 9a, clearly illustrating how increasing the shell thickness results in lowering the transition temperature. Furthermore, the cooperativity within the active core is affected since the transition transforms from first-order for uncoated particles to gradual conversion for core-shell systems, in excellent qualitative agreement with experimental results of Figure 2. The transition temperature, $T_{e q}$, estimated by the average of the transition temperatures on the cooling and heating branches of the cycle, are plotted vs $\omega$ in the inset of Figure 9a showing a continuous decrease when the thickness of the shell is increased.

Figure $9 \mathrm{~b}$ plots the zero temperature lattice parameters of the core and the shell as functions of the shell's thickness. As expected, the thinner shells are impacted to a larger extent by the volume shrinkage of the core upon its spin transition from HS to LS. $^{41,67}$ The shell lattice parameter decreases following the trends observed experimentally in Figure 3. However, the LS value for the core, set at $1 \mathrm{~nm}$ in the absence of a shell, steadily increases as the shell gets thicker, again qualitatively in agreement with the experimental observations. The larger LS lattice constant results in a smaller difference between LS and HS values when the core is coupled to the shell, thereby lowering the elastic interactions between the spin-crossover units ${ }^{67}$ and significantly impacting both the thermal and lightinduced spin transitions.

The present electro-elastic model can also be extended to study the photoexcitation process. We investigated an uncoated core as well as particles surrounded by 3 and $13 \mathrm{~nm}$ shells and the corresponding results are presented in Figure 10a. To include the photoexcitation process in the MC simulation, an additional term is introduced in the LS to HS transition probability of the MC detailed balance (see the Supporting Information). This new term depends on the intensity of the light and is equal to zero for the reverse HS $\rightarrow$ LS process. As depicted in Figures 10a and S7, the efficiency of the photoexcitation process depends on the shell's thickness, in very good agreement with the experimental observations of Figure 5. Indeed, the uncoated particle shows a slow and sigmoidal transformation, which accelerates significantly as the shell thickness increases, becoming almost exponential. The model also qualitatively reproduces the experimental trends in isothermal relaxation with the core-shell particles relaxing faster and the sigmoidal relaxation seen for the uncoated particles becoming exponential when coupled to a shell, Figure S8. 
a

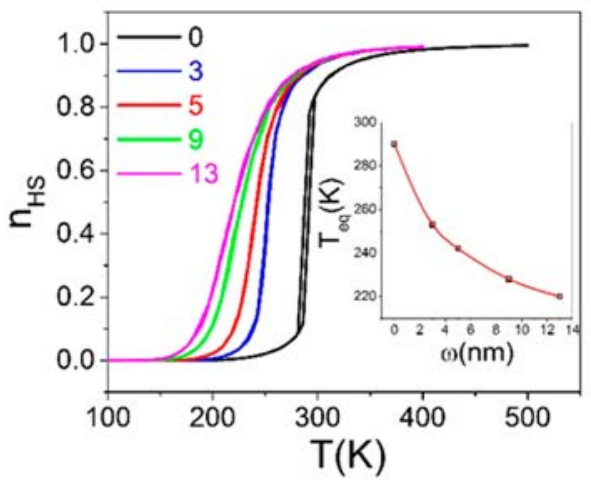

b

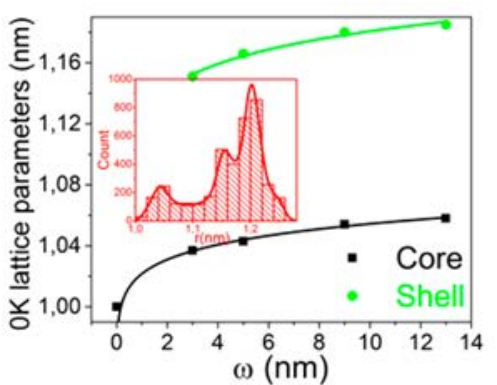

C

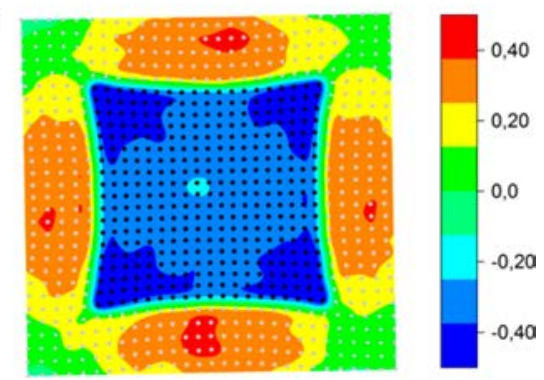

Figure 9. Predictions of the electro-elastic model. (a) Effect of shell thickness on the temperature dependence of the HS fraction, $n_{\mathrm{HS}}$. Inset: the equilibrium temperature, $T_{\mathrm{eq}}$, as a function of the shell thickness, $\omega$. (b) Lattice parameters of the core and the shell at $0 \mathrm{~K}$ as a function of shell thickness. Inset: $0 \mathrm{~K}$ histogram of the lattice parameters for the particle with a $13 \mathrm{~nm}$ shell over the entire particle, showing the broad distribution of distances. (c) Local pressure field distribution over a core-shell nanoparticle with $5 \mathrm{~nm}$ shell determined from the LS configuration at $0 \mathrm{~K}$. The following parameter values were used in the simulation: $\Delta=1500 \mathrm{~K}, g=150, A=8 \times 10^{5} \mathrm{~K} \cdot \mathrm{nm}^{-2}$ and $B=0.3 A$.

Evidence for Changes in Elastic Properties. The relative rigidity of the CoFe-PBA core in the LS state can be correlated with the change in lattice parameter upon undergoing the HS to LS transition. Cafun et al. ${ }^{68}$ have pointed out the lattice is less rigid in the HS state with longer and weaker cobalt-ligand bonds. In the core-shell particles, increasing shell thickness reduces the net contraction of the core upon cooling to the LS state, with the total change in lattice parameter decreasing from $\sim 0.34 \AA$ for the uncoated particles to $\sim 0.14 \AA$ for thicker shells, Figure 3. In fact, the dimensions of the relatively expanded LS lattice in the core-shell particles are closer to the HS CoFePBA lattice than the fully contracted LS state of uncoated particles. Therefore, as the net contraction of CoFe-PBA is
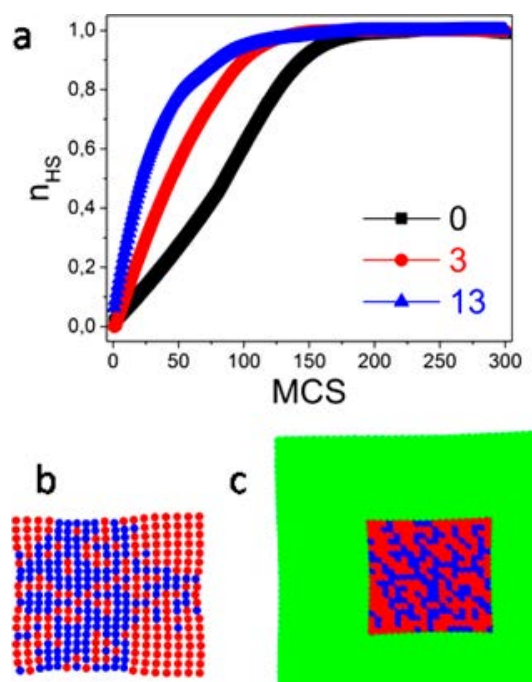

C

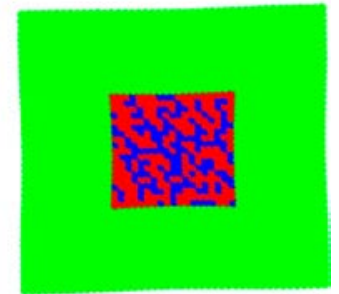

Figure 10. (a) High spin fraction vs time determined by the electroelastic model for $100 \mathrm{~K}$ photoexcitation of the core for various values of the shell thickness, $\omega$. Snapshots of the lattice during the photoexcitation process corresponding to $n_{\mathrm{HS}}=0.5$ for an uncoated core (b) and a core decorated with a shell of $13 \mathrm{~nm}$ width (c). Red, blue, and green points stand for the HS, LS, and shell sites, respectively.

limited in the core-shell particles, the rigidity corresponding to the LS phase decreases and hence the internal elastic forces responsible for the cooperative nature of the transition diminish. The change in lattice parameter and, as a result, the lower rigidity of the expanded LS CoFe-PBA phase correlate with the increased rate of the optically induced transition in core-shell particles, shown experimentally in Figure 5 and modeled in Figure 10. The less rigid core is better able to accommodate the change in volume associated with the transition, leading to faster rates.

Another influence of the shell is to exert stress on the core, favoring the HS state. These effects are predicted by the electro-elastic model and are seen experimentally when analyzing XRD data. The shell, with the larger lattice constant, exerts a tensile stress on the core while experiencing a compressive stress due to the core's smaller lattice constant. The misfit between core and shell components, $f$, is expressed as

$$
f=\frac{a_{2}-a_{1}}{a_{1}} \times 100 \%
$$

where $a_{1}$ and $a_{2}$ are the cubic lattice constants of the shell and core, respectively. For $\mathrm{RbCoFe} @ \mathrm{KNiCr}-\mathrm{PBA}$, the lattice parameter of the shell, $\sim 10.45 \AA$, is relatively close to that of the HS state of the uncoated core, $\sim 10.30 \AA$, resulting in a misfit of $f=-1.7 \%$ under the room temperature conditions used to prepare the particles. On the other hand, the magnitude of $f$ changes when the core contracts upon transitioning to the LS state. If the RbCoFe-PBA achieves the dimensions of the pure phase LS state, $a \sim 9.96 \AA$, the misfit becomes as large as $f=-4.7 \%$. It can be seen in Figures 3 and 9 that both core and shell are impacted by the contraction of the core, with changes observed in both lattices. The tensile force applied by the shell is seen in the restricted contraction of the core and the compressive force of the core results in distortion of the shell. These effects can be visualized in a pressure field distribution 
calculated by the electro-elastic model and shown in Figure 9c for a core-shell particle in the LS state. ${ }^{42,67}$

Experimentally, the strain each lattice experiences can be quantified from structural data via a Williamson-Hall analysis. ${ }^{69-71}$ Earlier work quantified the strain based on peak broadening in both CoFe-PBA and NiCr-PBA components before and after the CTIST of the core. ${ }^{59}$ The magnitude of microstrain, $\varepsilon$, in the NiCr-PBA shell at $100 \mathrm{~K}$ in the dark, with the CoFe-PBA in the LS state, is greatest for thin shells $\left(\varepsilon_{h k l}=\right.$ $\left.3.2 \% ; \varepsilon_{h 00}=1.4 \%\right)$ and decreases with increasing shell thickness $\left(\varepsilon_{h k l}=0.6 \% ; \varepsilon_{h 00}=0.2 \%\right) .{ }^{59}$ The analysis can be related to the ability of the shell to apply a stress on the core. The thinner shell is more pliable, so as the core contracts, the shell distorts and accommodates some of the compressive stress as lattice strain. As the shell becomes thicker, it is less susceptible to distortion, marked by a decrease in strain in the shell component, and the result is greater tensile force on the core, restricting its contraction. The tensile force influences the light-induced LS to HS CTIST. Once the transition is initiated by light, the tensile stress applied by the shell accelerates the associated structural changes. As the shell becomes thicker, the stress is larger, further accelerating the transition.

Changes to the Order of the Spin Transition in the Core. In general, as solids undergo spin transitions, domains of the new spin state nucleate and grow and the interplay between nucleation of new domains and growing established domains depends on the elastic properties of the lattice. During either the thermal or light-induced CTIST, the single phase CoFePBA exhibits coherent domain growth, characterized by the coexistence HS and LS domains during the transition, detectable with X-ray diffraction. Domain sizes on the order of 1000-3000 $\AA$ have been measured for the light-induced HS state. $^{72,73}$ The sizable mismatch between the lattice parameters of the HS and LS states results in considerable structural distortion, leading to a highly cooperative transition with longrange order. $^{74}$ For the core-shell particles, the X-ray data indicate the NiCr-PBA shell reduces the CoFe-PBA domain size during the thermal transition, Figure 4. In contrast to the uncoated particles, X-ray diffraction from the core-shell particles shows a continuous evolution of lattice constant through the transition, indicating the absence of large, welldefined HS and LS regions as the phase change progresses. Instead, the gradual transition is characteristic of a higher number of randomly distributed nucleation sites. The presence of the shell influences domain formation in the core by restricting the ability of the core to contract, thereby modulating intersite interactions. Cooperative interactions provide a barrier to new domain formation, so the reduction of these interactions results in a larger number of domains. ${ }^{75}$ The different behaviors are clearly demonstrated with the electro-elastic model in Figure 10, giving the spatial distribution of the HS and LS sites during the light-induced transition, showing the growth of larger domains for the uncoated particle and more ramified pattern of HS and LS structures for the nanoparticle with a thick shell.

The shell around the spin transition particle impacts two features known to influence the mechanism of the transition. First, cooperative spin transitions are often observed to initiate at low elastic energy sites, typically at a corner or edge of a particle or crystal. ${ }^{66,76}$ The shell modifies the core, changing the coordination sphere of those CoFe-PBA surface, edge, or corner sites that would otherwise serve as nucleation points for the transition in uncoated particles. Figure $10 \mathrm{~b}$ and $\mathrm{c}$ illustrates these different behaviors. The electro-elastic model also shows thicker shells broaden the distribution of nearest-neighbor distances in the LS core, Figure 9b inset, facilitating nucleation of new sites.

Restricting the ability of the core to contract is a second impact the shell has on the mechanism of the thermal spin transition. As the net contraction of the core is reduced, the difference between the energies of the HS and LS CoFe-PBA lattices decreases, which can be directly related to the extent of interaction between neighboring sites. ${ }^{42}$ The interaction parameter, $J$, which is commonly used to describe such nearest neighbor interactions, has been defined for spin crossover systems as

$$
J=A_{0} \rho_{1}^{2}
$$

where $A_{0}$ is derived from the experimental bulk modulus and $\rho_{1}$, which relates to the lattice misfit between the HS and LS lattice constants, is ${ }^{42}$

$$
\rho_{1}=\frac{1}{4}\left(R_{\mathrm{HH}}-R_{\mathrm{LL}}\right)
$$

By expressing the interaction parameter in terms of the bulk modulus, it becomes apparent that a reduction of rigidity can lead to a decrease in the interaction parameter, or the tendency for neighboring sites to be in similar spin states. A reduced net contraction of the core is expected to influence the interaction parameter in the same way. The result is that the presence of a shell, which modifies both the elasticity and the change in lattice parameter of the core, inhibits large single domain formation during the transition.

Further evidence that the shell facilitates the formation of core nucleation sites is seen in the different shapes of isothermal relaxation plots for the uncoated versus core-shell samples, Figures 6 and 7. The reduced barrier is quantifiable via the isothermal relaxation from the metastable high-spin state, Figure 8. The activation energy is at its maximum for the uncoated particle and decreases as the shell is added and becomes thicker. In addition, the relaxation curves for uncoated $\mathrm{RbCoFe}-\mathrm{PBA}$ particles are sigmoidal, in contrast to those for core-shell particles, which show a simple exponential decay. A sigmoidal relaxation from the metastable high-spin state is attributed to a highly cooperative transformation, which selfaccelerates once points of nucleation form..$^{3,41,42,77-80}$ The simple exponential form of the core-shell relaxation curves suggests a smaller level of cooperativity, consistent with the reduction of the intersite interaction parameter, and smaller volume change during the transition. In the case of core-shell systems, the lack of an initial plateaued region, also called the incubation regime, suggests that nucleation is a faster, lowerenergy process for the core-shell particles that takes place at very early times. ${ }^{80,81}$ These trends are well supported by the electro-elastic model. Starting from the initial photoinduced HS state, the isothermal relaxation of the uncoated nanoparticle shows sigmoidal behavior observed experimentally with the presence of an incubation time, characteristic of a cooperative system, Figures 11 and S8. In the case of the core-shell nanoparticles, the corresponding relaxation curves are exponentially shaped (see Figures $11 \mathrm{~b}$ and S8b), in excellent agreement with experimental data. 

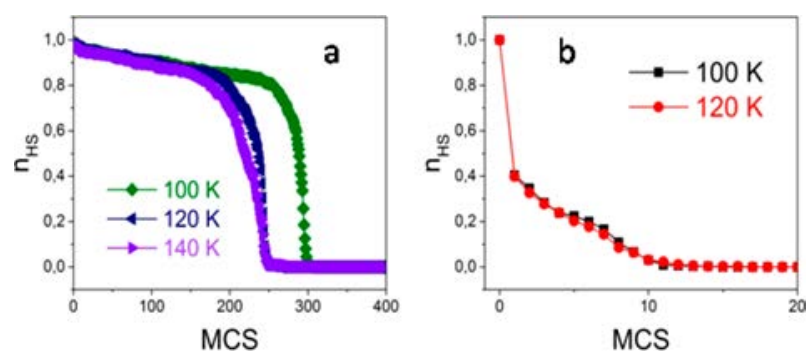

Figure 11. Monte Carlo simulations based on the electro-elastic model showing isothermal relaxations of the photoexcited metastable HS fraction for different temperatures for (a) an uncoated particle and (b) a core-shell particle ( shell width $=5 \mathrm{~nm}$ ). The sigmoidal character of the relaxation curves for the uncoated particles result from the domain nucleation and growth of the stable LS state, whereas the exponential decay observed for the core-shell particles ramified structure resulting from many random LS nucleation events.

\section{CONCLUSIONS}

The addition of a shell to mesoscale particles of the cyanometallate spin-transition network, $\mathrm{Rb}_{a} \mathrm{Co}_{b}\left[\mathrm{Fe}(\mathrm{CN})_{6}\right]_{c}$. $m \mathrm{H}_{2} \mathrm{O}$, dramatically alters the rate of the characteristic lightinduced CTIST. The behavior can be attributed through experiment and modeling to modifications of the elastic properties of the core by the shell. The normally large difference in lattice constant between HS and LS states of CoFe-PBA core is reduced in the core-shell particles. The larger low-spin-lattice constant lowers the rigidity of the LS CoFe-PBA phase, correlating with the increased rate of the optically induced transition in the core-shell particles. The smaller magnitude of the core expansion/contraction upon undergoing the spin transition, as mediated by the particle shell, also impacts the thermal CTIST processes. The smaller change directly relates to the extent of interaction between neighboring sites changing the cooperativity associated with the phase change. These trends are well supported by the numerical simulations. The findings are the first report of using heterostructure architecture or control of particle environment to influence the rate of an optically induced spin transition and should impact new strategies for using spin transition materials as photomechanical actuators.

\section{ASSOCIATED CONTENT}

\section{S Supporting Information}

The Supporting Information is available free of charge on the ACS Publications website at DOI: 10.1021/jacs.8b02148.

Pawley refinement for sample 8; plots of isothermal relaxation by PXRD; Arrhenius plots for samples 7-9 from PXRD; plots of isothermal relaxation by magnetometry for sample 7; Arrhenius plots for samples 6 and 7 from magnetometry; isothermal relaxation plots for sample 6; Monte Carlo simulations of the photoexcitation process at $100 \mathrm{~K}$; Monte Carlo simulations of the isothermal relaxation process; Parameters derived from isothermal relaxation; additional details of the particle synthesis and core-shell electro-elastic model. (PDF)

\section{AUTHOR INFORMATION}

\section{Corresponding Authors \\ *talham@chem.ufl.edu \\ *kamel.boukheddaden@uvsq.fr}

*meisel@phys.ufl.edu

ORCID

Kamel Boukheddaden: 0000-0003-0464-1609

Daniel R. Talham: 0000-0003-1783-5285

Notes

The authors declare no competing financial interest.

\section{ACKNOWLEDGMENTS}

This work was supported, in part, by the Division of Materials Research (DMR) at the National Science Foundation (NSF) under DMR-1405439 (D.R.T.), DMR-1202033 and DMR1708410 (M.W.M.). The Université de Versailles, University of Paris-Saclay, Universite de Sfax, and the University of Florida are acknowledged for their financial support. This research used resources of the Advanced Photon Source, a U.S. Department of Energy (DOE) Office of Science User Facility operated for the DOE Office of Science by Argonne National Laboratory. The authors thank Andrey Yakovenko and Wenquin $\mathrm{Xu}$ of the Advanced Photon Source for assistance with data collection methods for the time-dependent measurements under irradiation at APS beamline 17-BM-B.

\section{REFERENCES}

(1) Gütlich, P.; Garcia, Y.; Woike, T. Coord. Chem. Rev. 2001, 219, 839-879.

(2) Gütlich, P.; Garcia, Y.; Goodwin, H. A. Chem. Soc. Rev. 2000, 29, 419-427.

(3) Gütlich, P.; Hauser, A.; Spiering, H. Angew. Chem., Int. Ed. Engl. 1994, 33, 2024-2054.

(4) Hauser, A. Angew. Chem., Int. Ed. 2013, 52, 10419-10419.

(5) Mishima, A.; Koshiyama, T.; Real, J.; Ohba, M. J. Mater. Chem. C 2017, 5, 3706-3713.

(6) Ohba, M.; Yoneda, K.; Agusti, G.; Munoz, M.; Gaspar, A.; Real, J.; Yamasaki, M.; Ando, H.; Nakao, Y.; Sakaki, S.; Kitagawa, S. Angew. Chem., Int. Ed. 2009, 48, 4767-4771.

(7) Murphy, M.; Zenere, K.; Ragon, F.; Southon, P.; Kepert, C.; Neville, S. J. Am. Chem. Soc. 2017, 139, 1330-1335.

(8) (a) Neville, S. M.; Halder, G. J.; Chapman, K. W.; Duriska, M. B.; Moubaraki, B.; Murray, K. S.; Kepert, C. J. J. Am. Chem. Soc. 2009, 131, 12106-12108. (b) Southon, P. D.; Liu, L.; Fellows, E. A.; Price, D. J.; Halder, G. J.; Chapman, K. W.; Moubaraki, B.; Murray, K. S.; Letard, J. F.; Kepert, C. J. J. Am. Chem. Soc. 2009, 131, 10998-11009.

(9) (a) Coronado, E.; Espallargas, G. E. Chem. Soc. Rev. 2013, 42, 1525-1539. (b) Minguez Espallargas, G.; Coronado, E. Chem. Soc. Rev. 2018, 47, 533-557.

(10) Halder, G.; Kepert, C.; Moubaraki, B.; Murray, K.; Cashion, J. Science 2002, 298, 1762-1765.

(11) Reed, D.; Keitz, B.; Oktawiec, J.; Mason, J.; Runcevski, T.; Xiao, D.; Darago, L.; Rocell, V.; Bordiga, S.; Long, J. Nature 2017, 550 (7674), 96-100.

(12) Cobo, S.; Ostrovskii, D.; Bonhommeau, S.; Vendier, L.; Molnar, G.; Salmon, L.; Tanaka, K.; Bousseksou, A. J. Am. Chem. Soc. 2008, 130, 9019-9024.

(13) Manrique-Juarez, M. D.; Mathieu, F.; Shalabaeva, V.; Cacheux, J.; Rat, S.; Nicu, L.; Leichle, T.; Salmon, L.; Molnár, G.; Bousseksou, A. Angew. Chem., Int. Ed. 2017, 56, 8074-8078.

(14) Manrique-Juarez, M. D.; Rat, S.; Mathieu, F.; Saya, D.; Seguy, I.; Leichle, T.; Nicu, L.; Salmon, L.; Molnár, G.; Bousseksou, A. Appl. Phys. Lett. 2016, 109, 061903.

(15) Manrique-Juarez, M. D.; Rat, S.; Salmon, L.; Molnár, G.; Quintero, C. M.; Nicu, L.; Shepherd, H. J.; Bousseksou, A. Coord. Chem. Rev. 2016, 308, 395-408.

(16) Rat, S.; Nagy, V.; Suleimanov, I.; Molnar, G.; Salmon, L.; Demont, P.; Csoka, L.; Bousseksou, A. Chem. Commun. 2016, 52, 11267-11269. 
(17) Gural'skiy, I. A.; Quintero, C. M.; Costa, J. S.; Demont, P.; Molnar, G.; Salmon, L.; Shepherd, H. J.; Bousseksou, A. J. Mater. Chem. C 2014, 2, 2949-2955.

(18) Shepherd, H. J.; Gural'skiy, I. A.; Quintero, C. M.; Tricard, S.; Salmon, L.; Molnár, G.; Bousseksou, A. Nat. Commun. 2013, 4, 9.

(19) Sy, M.; Garrot, D.; Slimani, A.; Paez-Espejo, M.; Varret, F.; Boukheddaden, K. Angew. Chem., Int. Ed. 2016, 55, 1755-1759.

(20) Koo, Y. S.; Galan-Mascaros, J. R. Adv. Mater. 2014, 26, 67856789

(21) (a) Chen, Y. C.; Meng, Y.; Ni, Z. P.; Tong, M. L. J. Mater. Chem. C 2015, 3, 945-949. (b) Dugay, J.; Aarts, M.; Gimenéz-Marqués, M.; Kozlova, T.; Zandbergen, H. W.; Coronado, E.; van der Zant, H. S. J. Nano Lett. 2017, 17, 186-193.

(22) Suleimanov, I.; Kraieva, O.; Costa, J. S.; Fritsky, I. O.; Molnar, G.; Salmon, L.; Bousseksou, A. J. Mater. Chem. C 2015, 3, 5026-5032.

(23) Herrera, J.; Titos-Padilla, S.; Pope, S.; Berlanga, I.; Zamora, F.; Delgado, J.; Kamenev, K.; Wang, X.; Prescimone, A.; Brechin, E.; Colacio, E. J. Mater. Chem. C 2015, 3, 7819-7829.

(24) Titos-Padilla, S.; Herrera, J.; Chen, X.; Delgado, J.; Colacio, E. Angew. Chem., Int. Ed. 2011, 50, 3290-3293.

(25) Dia, N.; Lisnard, L.; Prado, Y.; Gloter, A.; Stephan, O.; Brisset, F.; Hafez, H.; Saad, Z.; Mathoniere, C.; Catala, L.; Mallah, T. Inorg. Chem. 2013, 52, 10264-10274.

(26) Presle, M.; Maurin, I.; Maroun, F.; Cortes, R.; Lu, L. L.; Hassan, R. S.; Larquet, E.; Guigner, J. M.; Riviere, E.; Wright, J. P.; Boilot, J. P.; Gacoin, T. J. Phys. Chem. C 2014, 118, 13186-13195.

(27) Felts, A.; Andrus, M.; Knowles, E.; Quintero, P.; Ahir, A.; Risset, O.; Li, C.; Maurin, I.; Halder, G.; Abboud, K.; Meisel, M.; Talham, D. J. Phys. Chem. C 2016, 120, 5420-5429.

(28) Gros, C. R.; Peprah, M. K.; Felts, A. C.; Brinzari, T. V.; Risset, O. N.; Cain, J. M.; Ferreira, C. F.; Meisel, M. W.; Talham, D. R. Dalton Trans. 2016, 45, 16624-16634.

(29) Risset, O.; Brinzari, T.; Meisel, M.; Talham, D. Chem. Mater. 2015, 27, 6185-6188.

(30) Dumont, M. F.; Knowles, E. S.; Guiet, A.; Pajerowski, D. M.; Gomez, A.; Kycia, S. W.; Meisel, M. W.; Talham, D. R. Inorg. Chem. 2011, 50, 4295-4300.

(31) Pajerowski, D. M.; Andrus, M. J.; Gardner, J. E.; Knowles, E. S.; Meisel, M. W.; Talham, D. R. J. Am. Chem. Soc. 2010, 132, 40584059.

(32) Tondu, B. Actuators 2015, 4, 336-352.

(33) Raza, Y.; Volatron, F.; Moldovan, S.; Ersen, O.; Huc, V.; Martini, C.; Brisset, F.; Gloter, A.; Stephan, O.; Bousseksou, A.; Catala, L.; Mallah, T. Chem. Commun. 2011, 47, 11501-11503.

(34) Pajerowski, D.; Ravel, B.; Li, C.; Dumont, M.; Talham, D. Chem. Mater. 2014, 26, 2586-2594.

(35) Qiu, D.; Gu, L.; Sun, X.; Ren, D.; Gu, Z.; Li, Z. RSC Adv. 2014, 4, 61313-61319.

(36) Bartual-Murgui, C.; Natividad, E.; Roubeau, O. J. Mater. Chem. C 2015, 3, 7916-7924.

(37) Félix, G.; Mikolasek, M.; Molnár, G.; Nicolazzi, W.; Bousseksou, A. Chem. Phys. Lett. 2014, 607, 10-14.

(38) Félix, G.; Nicolazzi, W.; Mikolasek, M.; Molnár, G.; Bousseksou, A. Phys. Chem. Chem. Phys. 2014, 16, 7358-7367.

(39) Felix, G.; Nicolazzi, W.; Salmon, L.; Molnár, G.; Perrier, M.; Maurin, G.; Larionova, J.; Long, J.; Guari, Y.; Bousseksou, A. Phys. Rev. Lett. 2013, 110, 235701.

(40) Félix, G.; Mikolasek, M.; Molnár, G.; Nicolazzi, W.; Bousseksou, A. Eur. J. Inorg. Chem. 2018, 2018, 435-442.

(41) Slimani, A.; Boukheddaden, K.; Yamashita, K. Phys. Rev. B: Condens. Matter Mater. Phys. 2014, 89, 214109.

(42) Oubouchou, H.; Slimani, A.; Boukheddaden, K. Phys. Rev. B: Condens. Matter Mater. Phys. 2013, 87, 104104.

(43) Linares, J.; Jureschi, C.; Boukheddaden, K. Magnetochemistry 2016, 2, 24.

(44) Linares, J.; Jureschi, C.; Boulmaali, A.; Boukheddaden, K. Physica B 2016, 486, 164-168.

(45) Muraoka, A.; Boukheddaden, K.; Linares, J.; Varret, F. Phys. Rev. B: Condens. Matter Mater. Phys. 2011, 84, 054119.
(46) Stoleriu, L.; Chakraborty, P.; Hauser, A.; Stancu, A.; Enachescu, C. Phys. Rev. B: Condens. Matter Mater. Phys. 2011, 84, 134102.

(47) Boukheddaden, K.; Slimani, A.; Sy, M.; Varret, F.; Oubouchou, H.; Traiche, R. In Magnetic Structures of $2 D$ and $3 D$ Nanoparticles: Properties and Applications; Levy, J.-C., Ed.; Pan Stanford Publishing: 2016; pp 333-434.

(48) Champion, G.; Escax, V.; Moulin, C. C. D.; Bleuzen, A.; Villain, F. O.; Baudelet, F.; Dartyge, E.; Verdaguer, M. J. Am. Chem. Soc. 2001, 123, 12544-12546.

(49) Escax, V.; Bleuzen, A.; Moulin, C. C. D.; Villain, F.; Goujon, A.; Varret, F.; Verdaguer, M. J. Am. Chem. Soc. 2001, 123, 12536-12543.

(50) Shimamoto, N.; Ohkoshi, S.; Sato, O.; Hashimoto, K. Inorg. Chem. 2002, 41, 678-684.

(51) Sato, O.; Einaga, Y.; Iyoda, T.; Fujishima, A.; Hashimoto, K. J. Electrochem. Soc. 1997, 144, L11-L13.

(52) Sato, O.; Iyoda, T.; Fujishima, A.; Hashimoto, K. Science 1996, 272, 704-705.

(53) Shimamoto, N.; Ohkoshi, S.; Sato, O.; Hashimoto, K. Inorg. Chem. 2002, 41, 678-684.

(54) Letard, J.-F. J. Mater. Chem. 2006, 16, 2550-2559.

(55) Decurtins, S.; Gutlich, P.; Hasselbach, K.; Hauser, A.; Spiering, H. Inorg. Chem. 1985, 24, 2174-2178.

(56) Decurtins, S.; Gutlich, P.; Kohler, C.; Spiering, H.; Hauser, A. Chem. Phys. Lett. 1984, 105, 1-4.

(57) Risset, O. N.; Quintero, P. A.; Brinzari, T. V.; Andrus, M. J.; Lufaso, M. W.; Meisel, M. W.; Talham, D. R. J. Am. Chem. Soc. 2014, 136, 15660-15669.

(58) Catala, L.; Brinzei, D.; Prado, Y.; Gloter, A.; Stéphan, O.; Rogez, G.; Mallah, T. Angew. Chem., Int. Ed. 2009, 48, 183-187.

(59) Felts, A. C.; Andrus, M. J.; Knowles, E. S.; Quintero, P. A.; Ahir, A. R.; Risset, O. N.; Li, C. H.; Maurin, I.; Halder, G. J.; Abboud, K. A.; Meisel, M. W.; Talham, D. R. J. Phys. Chem. C 2016, 120, 5420-5429.

(60) Abramoff, M. D.; Magalhaes, P. J.; Ram, S. J. Biophotonics Int. 2004, 11, 36.

(61) Toby, B. H.; Von Dreele, R. B. J. Appl. Crystallogr. 2013, 46, 544-549.

(62) Hammersley, A. P. FIT2D: An Introduction and Overview. ESRF Internal Report; Technical Report No. ESRF97HA02T; ESRF: Grenoble, 1997.

(63) Knowles, E. S. Strain-Mediated Photomagnetic Effects in Heterostructured Nanoparticles of Prussian Blue Analogues. Ph.D. Thesis, University of Florida, Gainesville, FL, 2013.

(64) Brinzei, D.; Catala, L.; Louvain, N.; Rogez, G.; Stephan, O.; Gloter, A.; Mallah, T. J. Mater. Chem. 2006, 16, 2593-2599.

(65) Chong, C.; Itoi, M.; Boukheddaden, K.; Codjovi, E.; Rotaru, A.; Varret, F.; Frye, F. A.; Talham, D. R.; Maurin, I.; Chernyshov, D.; Castro, M. Phys. Rev. B: Condens. Matter Mater. Phys. 2011, 84, 144102.

(66) Slimani, A.; Boukheddaden, K.; Varret, F.; Oubouchou, H.; Nishino, M.; Miyashita, S. Phys. Rev. B: Condens. Matter Mater. Phys. 2013, 87, 014111.

(67) Slimani, A.; Khemakhem, H.; Boukheddaden, K. Phys. Rev. B: Condens. Matter Mater. Phys. 2017, 95, 174104.

(68) Cafun, J.-D.; Cartier dit Moulin, C.; Fornasieri, G.; Arrio, M.-A.; Briois, V.; Bleuzen, A. New J. Chem. 2011, 35, 2074-2080.

(69) Williamson, G. K.; Hall, W. H. Acta Metall. 1953, 1, 22-31.

(70) van Berkum, J. G. M.; Delhez, R.; de Keijser, T. H.; Mittemeijer, E. J. Acta Crystallogr., Sect. A: Found. Crystallogr. 1996, A52, 730-747.

(71) Scardi, P.; Leoni, M.; Delhez, R. J. Appl. Crystallogr. 2004, 37, 381-390.

(72) Hanawa, M.; Moritomo, Y.; Kuriki, A.; Tateishi, J.; Kato, K.; Takata, M.; Sakata, M. J. Phys. Soc. Jpn. 2003, 72, 987-990.

(73) Escax, V.; Bleuzen, A.; Itié, J. P.; Munsch, P.; Varret, F.; Verdaguer, M. J. Phys. Chem. B 2003, 107, 4763-4767.

(74) Sato, O.; Einaga, Y.; Fujishima, A.; Hashimoto, K. Inorg. Chem. 1999, 38, 4405-4412.

(75) Slimani, A.; Boukheddaden, K.; Yamashita, K. Phys. Rev. B: Condens. Matter Mater. Phys. 2015, 92, 014111. 
(76) Nishino, M.; Enachescu, C.; Miyashita, S.; Rikvold, P. A.; Boukheddaden, K.; Varret, F. Sci. Rep. 2011, 1, 162-167.

(77) Hauser, A.; Jeftic, J.; Romstedt, H.; Hinek, R.; Spiering, H. Coord. Chem. Rev. 1999, 190-192, 471-491.

(78) Degert, J.; Lascoux, N.; Montant, S.; Létard, S.; Freysz, E.; Chastanet, G.; Létard, J. F. Chem. Phys. Lett. 2005, 415, 206-210.

(79) Slimani, A.; Boukheddaden, K.; Varret, F.; Nishino, M.; Miyashita, S. J. Chem. Phys. 2013, 139, 194706.

(80) Slimani, A.; Varret, F.; Boukheddaden, K.; Chong, C.; Mishra, H.; Haasnoot, J.; Pillet, S. Phys. Rev. B: Condens. Matter Mater. Phys. 2011, 84, 094442.

(81) Hoo, B.; Boukheddaden, K.; Varret, F. Eur. Phys. J. B 2000, 17 (3), 449-457. 